\title{
Effects of Radon and UV Exposure on Skin Cancer Mortality in Switzerland
}

\section{Danielle Vienneau, ${ }^{1,2}$ Kees de Hoogh, ${ }^{1,2}$ Dimitri Hauri, ${ }^{3,4}$ Ana M. Vicedo-Cabrera, ${ }^{1,2}$ Christian Schindler, ${ }^{1,2}$ Anke Huss, ${ }^{5}$ and Martin Röösli ${ }^{1,2}$ for the SNC Study Group}

\author{
${ }^{1}$ Department of Epidemiology and Public Health, Swiss Tropical and Public Health Institute, Basel, Switzerland \\ ${ }^{2}$ University of Basel, Basel, Switzerland \\ ${ }^{3}$ Federal Statistical Office, Neuchâtel, Switzerland \\ ${ }^{4}$ ImmoCompass AG, Zurich, Switzerland \\ ${ }^{5}$ Institute for Risk Assessment Sciences, University Utrecht, Utrecht, the Netherlands
}

BACKGROUND: Skin cancer incidence in Switzerland is among the highest in the world. In addition to exposure to ultraviolet (UV) radiation, radon alpha particles attached to aerosols can adhere to the skin and potentially cause carcinogenic effects.

OвJECTIVEs: We investigated the effects of radon and UV exposure on skin cancer mortality.

Methods: Cox proportional hazard regression was used to study the association between exposures and skin cancer mortality in adults from the Swiss National Cohort. Modeled radon exposure and erythemal-weighted UV dose were assigned to addresses at baseline. Effect estimates were adjusted for sex, civil status, mother tongue, education, job position, neighborhood socioeconomic position, and UV exposure from outdoor occupation.

RESults: The study included 5.2 million adults (mean age $48 \mathrm{y}$ ) and 2,989 skin cancer deaths, with 1,900 indicating malignant melanoma (MM) as the primary cause of death. Adjusted hazard ratios (HR) for MM at age 60 were 1.16 (95\% CI: 1.04, 1.29) per $100 \mathrm{~Bq} / \mathrm{m}^{3} \mathrm{radon}$ and $1.11(1.01,1.23)$ per $\mathrm{W} / \mathrm{m}^{2}$ in UV dose. Radon effects decreased with age. Risk of MM death associated with residential UV exposure was higher for individuals engaged in outdoor work with UV exposure (HR 1.94 [1.17, 3.23]), though not statistically significantly different compared to not working outdoors (HR $1.09[0.99,1.21], p=0.09)$.

Conclusions: There is considerable variation in radon and UV exposure across Switzerland. Our study suggests both are relevant risk factors for skin cancer mortality. A better understanding of the role of the UV radiation and radon exposure is of high public health relevance. https://doi.org/ 10.1289/EHP825

\section{Introduction}

Switzerland is among the countries with the highest agestandardized incidence rates of malignant melanoma (MM), third after Australia and New Zealand (20.3, 35.8, and 34.9 per 100,000, respectively, in 2012) (IARC 2013). Interestingly, agestandardized incidence rates for cutaneous melanoma in Swiss and Austrian Tyrol cancer registries are considerably higher than in other central European cancer registries (Moehrle and Garbe 1999). For example, the rates for 2012 in Germany and France are 11.4 and 10.2 per 100,000, respectively (IARC 2013). One obvious explanation may be the higher ultraviolet (UV) exposure at higher elevations, with UV considered the most important risk factor (Aceituno-Madera et al. 2011). Recent findings suggest that radon exposure also plays a role (Bräuner et al. 2015).

Radon is a ubiquitous radioactive gas and is the decay product of uranium, a naturally occurring element in granitic and metamorphic rocks. Population exposure to radon is thus mainly determined by the underlying geology of the environment. In Switzerland, average radon exposure is on the order of $78 \mathrm{~Bq} / \mathrm{m}^{3}$ (Menzler et al. 2008) to $84 \mathrm{~Bq} / \mathrm{m}^{3}$ (Hauri et al. 2012), which is higher than in other European countries.

\footnotetext{
Address correspondence to D. Vienneau, Department of Epidemiology and Public Health, Swiss Tropical and Public Health Institute, Socinstrasse 57, CH-4051, Basel, Switzerland. Telephone: 41 (0) 61-284-8398. E-mail: danielle.vienneau@unibas.ch

Supplemental Material is available online (https://doi.org/10.1289/EHP825).

The authors declare they have no actual or potential competing financial interests.

Received 19 July 2016; Revised 28 October 2016; Accepted 15 November 2016; Published 16 June 2017.

Note to readers with disabilities: $E H P$ strives to ensure that all journal content is accessible to all readers. However, some figures and Supplemental Material published in $E H P$ articles may not conform to 508 standards due to the complexity of the information being presented. If you need assistance accessing journal content, please contact ehponline@niehs.nih.gov. Our staff will work with you to assess and meet your accessibility needs within 3 working days.
}

It is well known that, after smoking, radon is the secondleading cause of lung cancer, accounting for an estimated 3-14\% of cases (Krewski et al. 2006; WHO 2009). In Switzerland, radon has been estimated to account for nearly $10 \%$ of lung cancer cases (Menzler et al. 2008). As such, radon has been listed as carcinogenic by the World Health Organization (WHO 2009) and the IARC (2001). Inhaled radon decay products deposit in the respiratory tract where they further decay and can irradiate lung tissues (Kendall and Smith 2002), leading to DNA damage (WHO 2009). Environmental radon is also relevant for skin exposure because radon attaches to aerosol particles in the air, which adhere to the human skin via electrostatic attraction. Subsequently, the skin's outer layer is irradiated by the alpha particles from radon decay (Eatough 1997). Annual dose to the skin at $200 \mathrm{~Bq} / \mathrm{m}^{3}$ is estimated to be $25 \mathrm{mSv}$ (Eatough and Henshaw 1992). As such, the skin receives by far the second-highest dose after the respiratory tract; ranked from highest to lowest, average doses are 97, 2.9, and $<1 \mathrm{mSv}$ respectively, for the lung, kidney, and all other organs (Kendall and Smith 2002).

Although causality was not established, theoretical dosimetric calculations in the United Kingdom found that $0.7 \%$ [95\% confidence interval (CI): $0.5,5.0 \%$ ] of skin cancers are attributable to the nominal UK indoor radon level of $20 \mathrm{~Bq} / \mathrm{m}^{3}$ (Charles 2007). An ecologic study in the southwest United Kingdom by Wheeler et al. (2012) found a higher risk of squamous cell carcinoma in areas with higher mean radon levels [relative risk (RR) $1.76(95 \% \mathrm{CI}: 1.46,2.11)]$ for areas $\geq 230 \mathrm{~Bq} / \mathrm{m}^{3}$ versus $0-39$ $\left.\mathrm{Bq} / \mathrm{m}^{3}\right)$, and a recent cohort study in Denmark reported an association between long-term residential radon exposure and incidence of basal cell carcinoma [incidence rate ratio (IRR) 1.14 (95\% CI : $1.03,1.27)$ per $100 \mathrm{~Bq} / \mathrm{m}^{3}$ ) (Bräuner et al. 2015).

Because of large differences in altitude and a wide variation in geology and soils, the gradients for both UV and radon exposure are considerable in Switzerland. With the high incidence of skin cancer, exploring the effects of radon and UV radiation on skin cancer risk is clearly a public health priority in Switzerland. In this study, we aimed to investigate the effects of radon and UV radiation exposure on skin cancer mortality. 


\section{Methods}

\section{Swiss National Cohort}

Our analysis is based on data from the Swiss National Cohort (SNC), a national longitudinal research platform linking census data with birth, mortality, and emigration data. The SNC was approved by the Ethics Committees of the Cantons of Zurich and Bern (Bopp et al. 2009). Owing to mandatory participation, nearly all persons residing in Switzerland at the time of the 1990 and 2000 censuses are represented; an estimated 98.6\% residents participated in 2000 (Renaud 2004). For each person, the SNC contains an individual (e.g., sex, date of birth, occupation), household [e.g., type of household, socioeconomic position (SEP)], and building (e.g., type of building, number of floors, geographical coordinate) record. We included persons living in Switzerland $\geq 20$ y old on 4 December 2000 (date of the census).

For the main outcome, we considered deaths where malignant melanoma (MM) was identified as the definitive primary cause of death. We also investigated nonmelanoma skin cancer (NMSC), which has a much lower case-fatality. Mortality records in the SNC are based on coding of death certificates, and cases are identified by Internationational Classification of Diseases and Related Health Problems, 10th edition (ICD10) codes C43 (MM) and C44 (NMSC) (WHO 2016).

\section{Exposure Assessment}

Annual mean radon and UV exposure estimates were assigned to the addresses of SNC participants at baseline on the basis of $x-y$ coordinates and, for radon, floor of residence.

Radon exposure was based on a national exposure prediction model developed and validated with 44,631 measurements from the Swiss Radon Database from 1994-2004. The radon prediction model included underlying geology (tectonic unit), soil texture, degree of urbanization, dwelling type, year of construction of the building, and floor of the residential dwelling (Hauri et al. 2012). Explaining 20\% overall variability, the model was determined to be robust through validation with an independent radon data set [Spearman's rank correlation was 0.45 (95\% CI: 0.44 , 0.46 ) for model development, $n=35,706$, and 0.44 (95\% CI: $0.42,0.46$ ) in validation, $n=8,925)$.

Long-term residential UV exposure, measured as erythemalweighted radiation (UVEry) dose in watts per square meter $\left(\mathrm{W} / \mathrm{m}^{2}\right)$, was modeled from UV-Index (UVI) measurements (MeteoSwiss 2017) and $2 \mathrm{~km} \times 2 \mathrm{~km}$ global radiation (Stöckli 2013) and a $25 \mathrm{~m} \times 25 \mathrm{~m} 8$ digital terrain model for Switzerland (Swisstopo 2004). Global radiation data from MeteoSwiss, based on the Heliosat algorithm, takes account of shadow, albedo, and the sky-view factor. Infrared satellite data are used to distinguish snow from clouds. The annual absolute mean bias difference is $10 \mathrm{~W} / \mathrm{m}^{2}$ in flat terrain and $\leq 30 \mathrm{~W} / \mathrm{m}^{2}$ in the mountains. Estimates are generally more accurate during no to light cloud conditions and from May to September. We obtained NetCDF files for the monthly global radiation data [i.e., Surface Incoming Shortwave Radiation (SIS)] W/m² from 2004 to 2013. The monthly data were extracted as rasters and were reprojected into the Swiss national projection (CH-1903). Daily maximum UVI data were also obtained from MeteoSwiss for 4 monitoring stations (Payerne, Davos, Jungfraujoch, and Locarno). We calculated the monthly average to coincide with the temporal resolution of the solar radiation data. The geocoded UV monitoring site locations were mapped in a geographic information system and intersected with the series of solar radiation grids. We then calculated the long-term monthly UVI and solar radiation by averaging over the period 2004-2008. A linear mixed-effects regression model was applied to predict UVI on the basis of solar radiation and altitude (Equation 1). The model was evaluated by applying it to later years not included in the model building, giving an adjusted $\mathrm{R}^{2}=0.95$ and standard error of the estimate $(\mathrm{SEE})=0.60$ :

$$
\begin{array}{r}
\text { PredUVI }=\exp \left[-1.05+(0.02 \times \text { SolRad })+\left(0.00003 \times(\text { SolRad })^{2}\right]\right. \\
+(0.0698 \times \text { Altitude_km }))
\end{array}
$$

where, PredUVI is the predicted UVI, SolRad is the long-term solar radiation; and Altitude_km is altitude from the digital terrain model measured in $\mathrm{km}$.

Finally, we converted modeled UVI to erythemal-weighted radiation (UVEry) dose using Equation 2 from the literature (McKenzie et al. 2004):

$$
\text { UVEry }\left[\text { in } \mathrm{W} / \mathrm{m}^{2}\right]=\text { PredUVI } / 0.4
$$

where, UVEry is the erythemal-weighted radiation, and PredUVI is the predicted UVI from Equation 1.

We obtained a job exposure matrix (JEM) for occupational exposure to UV, specifically including solar UV radiation via outdoor occupation (Guénel et al. 2001). The JEM was recoded from 5-digit ISCO68 to ISCO88 and matched to the indicated occupation of study participants to define an indicator variable (yes, no) for UV exposure from outdoor occupation at baseline.

\section{Statistical Analysis}

The association of UVEry and radon exposure with skin cancer mortality was investigated by stratified Cox regression (baseline hazard stratified by sex), with age as the underlying time axis. We observed individual survival histories from 4 December 2000 through 31 December 2008 among subjects who were $\geq 20$ y old at the start of follow-up, and we applied right censoring at the age of emigration, at the age of death from a cause other than skin cancer, or at the end of follow-up. We tested the proportional hazard (PH) assumption using Schoenfeld residuals. Because the hazard ratio of radon decreased with age, an interaction term (radon $\times$ age) was introduced along with the sex stratification to satisfy the $\mathrm{PH}$ assumption. Hazard ratios (HRs) are expressed per $100 \mathrm{~Bq} / \mathrm{m}^{3}$ increase in radon at age 60 (approximate mean age, to reflect population distribution), and per $1 \mathrm{~W} / \mathrm{m}^{2}$ increase in UVEry. To compare the HRs of the two exposures, results were also expressed per interquartile range (IQR). All models were adjusted for sex, civil status (single, married, widowed, divorced), education (compulsory or less, upper secondary, tertiary, unknown), quartiles of neighborhood socioeconomic position (Panczak et al. 2012), having outdoor occupation with UV exposure (based on the JEM), and mother tongue (German, French, Italian, other) to reflect differences in lifestyle and cultural attitudes and because skin pigmentation differs between European populations (Moehrle and Garbe 1999). Additional potential confounders were assessed (though not included) using the likelihood ratio test and a change-in-estimate criterion of $10 \%$ (Greenland 1989): Swiss region (Lake Geneva, Espace Mittelland, Northwest, Zurich, East, Central, and Ticino), degree of urbanization (urban, intermediate, rural), and job attainment (high, medium, low, other). Skin cancer may be related to SEP (i.e., vacation behavior). We therefore included glioma (ICD10: C71, definitive primary cause of death) as a negative control outcome (Lipsitch et al. 2010) because it is associated with SEP (Khanolkar et al. 2016).

The main model considered MM as the definitive primary cause of death. In sensitivity analysis S1, we explored all MM deaths (i.e., all $=$ definitive primary cause, concomitant disease, consecutive disease, or initial disease). We further combined MM and NMSC to explore primary (S2) and all (S3) skin cancer deaths, and we looked separately at all NMSC (S4). Models were 
repeated for those who had lived at the same address between the 1990 and 2000 censuses, considered "nonmovers." We also evaluated the impact of shifting all retirees from the "no" UV exposure from outdoor occupation group to "unknown."

We explored potential effect modification by including interaction terms between sex, outdoor occupation, and mother tongue and each of the two exposures; effect modification was assessed using the likelihood ratio test and was confirmed by running stratified models. We also tested for an interaction between the two exposures.

\section{Results}

A total of 7.29 million persons were recorded in the 2000 census. Of these, 1,670,536 (22.9\%) were excluded because they were $<20 \mathrm{y}$ of age at baseline, and 359,206 (4.9\%) were excluded because of missing building coordinates. A further 1,042 (0.01\%) persons were excluded because of missing covariate information on socioeconomic position. Thus, the analyses were based on 5,249,462 individuals accounting for 40,805,591 person-years, a mean follow-up of $7.8 \mathrm{y}$ and 2,989 deaths from all recorded skin cancers.

The distribution of specific population characteristics is described in Table 1 for the entire population and for different subgroups (including nonmovers and different categories of skin cancer deaths). Over $60 \%$ of the cohort participants were married, German-speaking, residing in urban areas, and had upper secondary education or higher; $43 \%$ had a medium to high job position, and $4.6 \%$ worked in outdoor occupations with UV exposure. Most of the characteristics showed similar distributions in both nonmovers and the entire population, with a total of $48 \%$ who did not move between the two census years 1990 and 2000. Slightly more males than females died from skin cancer during the follow-up. The negative control outcome is presented in Table $\mathrm{S} 1$.

Figure 1 maps the range of exposures across the study population averaged at the community level $(n=2,896)$. At the individual level, the mean (IQR) for the full study population was 91.8 (47.8) $\mathrm{Bq} / \mathrm{m}^{3}$ for radon and $8.5(0.7) \mathrm{W} / \mathrm{m}^{2}$ for UVEry dose (Table 1; see Figure S1 for histograms). Radon exposure in $0.25 \%$ of the population exceeded the current (and proposed) WHO guideline level of 300 (100) Bq/ $\mathrm{m}^{3}$ (WHO 2009). Radon and UVEry exposure were not correlated at the individual level $(r=-0.01)$.

Table 2 presents the results from the stratified Cox regression models for skin cancer deaths, mutually adjusted for the alternate exposure, for the full study sample and for nonmovers. After adjustment, our main model showed statistically significant positive associations with both exposures and malignant melanoma mortality, with HRs of 1.16 (95\% CI: $1.04,1.29)$ per $100 \mathrm{~Bq} / \mathrm{m}^{3}$ for radon and $1.11(1.01,1.23)$ per $\mathrm{W} / \mathrm{m}^{2} \mathrm{UVEry}$. Sex-specific HRs for radon, computed for ages $30,45,60$, and $75 \mathrm{y}$, are given in Figure 2. A slightly stronger downward trend is apparent for males compared with females. The HRs for the two exposures are similar when expressed per IQR [1.07 (95\% CI: 1.02, 1.13) vs. 1.08 (95\% CI: 1.01, 1.15), respectively, for radon and UVEry, M2 main model] (see Table S2). We found no interaction between the two exposures $\left[\chi^{2}(1)=0.02, p=0.88\right]$. No increased risk in relation to either exposure was found for glioma $(n=3,004$ deaths): $\mathrm{HR}=1.02$ (95\% CI: $0.94,1.10)$ per $100 \mathrm{~Bq} / \mathrm{m}^{3}$ radon and 0.96 (95\% CI: $0.89,1.04)$ per $\mathrm{W} / \mathrm{m}^{2}$ UVEry (see Table S3). It is thus unlikely that our associations are explained by residual confounding from SEP.

Sensitivity analyses (Table 2) showed statistically significant HRs for radon exposure in the full study sample and nonmovers for most outcomes. The exception was S4 (restricted to NMSC), for which there was a small proportion of deaths. Although we found positive associations between UVEry and skin cancer in the full study population, associations were only borderline significant for all MM (S1; $p=0.09)$ and all NMSC (S4; $p=0.14)$.

The associations were not modified by sex or mother tongue (Table 3). However, the HR for UVEry was higher for persons engaged in outdoor occupations with UV exposure than for others [1.94 (95\% CI: 1.17, 3.23) vs. 1.09 (95\% CI: 0.99, 1.21) per $\left.\mathrm{W} / \mathrm{m}^{2}\right]$, although the difference was not quite statistically significant $(p=0.09)$.

\section{Discussion}

We found a statistically significant increased risk of death from malignant melanoma and skin cancer in general, independent of UVEry, in adults associated with exposure to radon. Interestingly, the risk when expressed per IQR in exposure is similar for radon and UVEry. The effect of UV on skin cancer mortality, however, is expected to be an underestimation given that we only modeled residential exposure and did not take into account personal behavior and vacation habits. Dadvand et al. (2011) reported that ambient UV levels account for only a small portion, approximately one-fifth, of the variation in facial exposure levels. For radon, modeling residential exposure is expected to produce less exposure misclassification.

Worldwide, Switzerland has amongst the highest skin cancer incidence. In part, this may be related to the wealth and behavior of the population leading to recreational UV radiation exposure. Many persons may have traveled south for vacations before this luxury was accessible to the general population in Europe, and on average, more people in Switzerland engage in outdoor physical activity (72\% vs. 32\% average for Europe) (FSO 2013; WHO 2006). Natural UV levels are also relatively high owing to the elevation in the alpine regions. In addition, certain areas of Switzerland have elevated radon levels because of the underlying geology, which leads to high doses of radon (31\% adults exposed $>100 \mathrm{~Bq} / \mathrm{m}^{3}$ ).

The HR for radon and MM death ranged from 1.41 (95\% CI: $1.09,1.80)$ at $30 \mathrm{y}$ to $1.05(0.94,1.18)$ at 75 years of age per $100 \mathrm{~Bq} / \mathrm{m}^{3}$. This decrease in risk with age is plausible with the observation that sensitivity to ionizing radiation decreases with age. For example, the excess relative risk of cancer in Japanese atomic bomb survivors was twice as high after exposure at age 10 compared to exposure at age 40 (Douple et al. 2011). We found similar point estimates for MM and NMSC in the full study sample (Table 2); however, the association for NMSC and radon was not statistically significant likely because of the smaller number of cases. Furthermore, the point estimate for MM was highest in individuals residing long-term at the same address, where exposure misclassification is reduced. NMSC and MM mortality are linked to chronic and intermittent UV exposure, respectively (Berwick et al. 2008). Our model of long-term residential UVEry levels is more representative of chronic exposure. We can, however, assume that areas with higher average UV also have a greater probability for higher acute exposures. The likelihood of this assumption is reflected in our results, where we observed statistically significant effects for UVEry and MM mortality.

Despite the small number of individuals exposed to UV through outdoor occupation (4.6\%), stratified analysis showed a compelling pattern for the two exposures. Though the $p$-values for interaction were not significant, UVEry dose seems more relevant for malignant melanoma mortality in individuals with outdoor occupations, whereas radon exposure may be more important for those not working outdoors (Table 3). The large nonexposed group, however, may be subject to exposure misclassification. We can only speculate that these individuals spent the majority of their time indoors, either working or 
Table 1. Population characteristics and deaths due to skin cancer $(n=5,249,462)$.

\begin{tabular}{|c|c|c|c|c|c|c|c|}
\hline \multirow[b]{2}{*}{ Characteristic } & \multicolumn{2}{|c|}{ Cohort } & \multicolumn{5}{|c|}{ Deaths $^{a}$} \\
\hline & $\begin{array}{l}\text { Full study } \\
\text { sample }\end{array}$ & Nonmovers & $\begin{array}{l}\text { MM primary } \\
\text { (main model) }\end{array}$ & $\begin{array}{l}\text { MM all } \\
(\mathrm{S} 1)\end{array}$ & $\begin{array}{l}\text { MM + NMSC } \\
\text { primary (S2) }\end{array}$ & $\begin{array}{l}\mathrm{MM}+\mathrm{NMSC} \\
\text { all (S3) }\end{array}$ & $\begin{array}{l}\text { NMSC all } \\
\text { (S4) }\end{array}$ \\
\hline \multicolumn{8}{|l|}{ Age } \\
\hline Range & $20.0-106.1$ & $20.0-106.1$ & 20.3-97.7 & 20.3-97.7 & $20.3-100.3$ & $20.2-100.3$ & $27.3-100.3$ \\
\hline \multicolumn{8}{|l|}{$\operatorname{Sex}, n(\%)$} \\
\hline Male & $2,535,842(48.3)$ & $1,183,084(47.4)$ & $1,092(57.5)$ & $1,235(57.3)$ & $1,365(58.1)$ & $1,728(57.8)$ & $496(59.2)$ \\
\hline Female & $2,713,620(51.7)$ & $1,312,931(52.6)$ & $808(42.5)$ & $922(42.7)$ & $984(41.9)$ & $1,261(42.2)$ & $342(40.8)$ \\
\hline Married & $3,286,724(62.6)$ & $1,658,643(66.5)$ & 1,304 (68.6) & $1,452(67.3)$ & $1,561(66.5)$ & $1,887(63.1)$ & $440(52.5)$ \\
\hline Widowed & $354,562(6.8)$ & $260,613(10.4)$ & $283(14.9)$ & $356(16.5)$ & $408(17.4)$ & $638(21.3)$ & $283(33.8)$ \\
\hline Divorced & $380,172(7.2)$ & $136,797(5.5)$ & $123(6.5)$ & $140(6.5)$ & $149(6.3)$ & $184(6.2)$ & $44(5.3)$ \\
\hline \multicolumn{8}{|l|}{ Mother tongue, $n(\%)$} \\
\hline German & $3,377,019(64.3)$ & $1,699,651(68.1)$ & $1,410(74.2)$ & $1,604(74.4)$ & $1,707(72.7)$ & $2,184(73.1)$ & $584(69.7)$ \\
\hline French & $1,037,545(19.8)$ & $504,472(20.2)$ & $342(18.0)$ & $393(18.2)$ & $462(19.7)$ & $591(19.8)$ & $200(23.9)$ \\
\hline Italian & $372,662(7.1)$ & $195,761(7.8)$ & $107(5.6)$ & $113(5.2)$ & $129(5.5)$ & $155(5.2)$ & $42(5.0)$ \\
\hline Tertiary level education & $1,092,115(20.8)$ & $427,330(17.1)$ & $415(21.8)$ & $450(20.9)$ & $483(20.6)$ & $571(19.1)$ & $121(14.4)$ \\
\hline Not known & $142,558(2.7)$ & $24,587(1.0)$ & $21(1.1)$ & $26(1.2)$ & $23(1.0)$ & $38(1.3)$ & $12(1.4)$ \\
\hline \multicolumn{8}{|l|}{ Geographic region, $n(\%)$} \\
\hline Lake Geneva & $936,047(17.8)$ & $430,820(17.3)$ & $300(15.8)$ & $335(15.5)$ & $400(17.0)$ & $497(16.6)$ & 164 (19.6) \\
\hline Espace Mittelland & $1,208,921(23.0)$ & 613,749 (24.6) & $491(25.8)$ & $562(26.1)$ & $618(26.3)$ & $788(26.4)$ & $226(27.0)$ \\
\hline Northwestern Switzerland & $732,406(14.0)$ & 361,965 (14.5) & 264 (13.9) & $300(13.9)$ & $310(13.2)$ & $399(13.3)$ & $100(11.9)$ \\
\hline Zurich & $930,514(17.7)$ & $387,148(15.5)$ & $325(17.1)$ & $364(16.9)$ & $382(16.3)$ & $487(16.3)$ & $123(14.7)$ \\
\hline Eastern Switzerland & $729,672(13.9)$ & $351,222(14.1)$ & 277 (14.6) & $316(14.6)$ & $334(14.2)$ & $431(14.4)$ & $117(14.0)$ \\
\hline Central Switzerland & $473,517(9.0)$ & $232,167(9.3)$ & $165(8.7)$ & $195(9.0)$ & $206(8.8)$ & $269(9.0)$ & $75(8.9)$ \\
\hline Ticino & $238,385(4.5)$ & $118,944(4.8)$ & $78(4.1)$ & $85(3.9)$ & $99(4.2)$ & $118(3.9)$ & $33(3.9)$ \\
\hline \multicolumn{8}{|l|}{ Job Position, $n(\%)^{c}$} \\
\hline High & $415,846(7.9)$ & $140,618(5.6)$ & $100(5.3)$ & $107(5.0)$ & $104(4.4)$ & $116(3.9)$ & $9(1.1)$ \\
\hline Medium & $1,863,641(35.5)$ & $737,282(29.5)$ & $368(19.4)$ & $388(18.0)$ & $396(16.9)$ & $423(14.2)$ & $35(4.2)$ \\
\hline Yes & 240,777 (4.6) & $120,647(4.8)$ & $51(2.7)$ & $52(2.4)$ & $55(2.3)$ & $59(2.0)$ & $8(1.0)$ \\
\hline \multicolumn{8}{|l|}{ Radon exposure, $\mathrm{Bq} / \mathrm{m}^{3}$} \\
\hline Mean (SD) & $91.8(45.6)$ & $95.7(47.4)$ & $95.2(48.8)$ & $94.8(48.7)$ & $95.7(49.9)$ & $95.0(49.2)$ & $95.5(50.3)$ \\
\hline Range & $5.2-472.0$ & $5.6-472.0$ & $18.1-394.3$ & $18.1-394.3$ & $18.1-394.3$ & $16.7-394.3$ & $16.7-336.3$ \\
\hline Interquartile range & 47.8 & 50.2 & 47.8 & 48.0 & 49.3 & 48.7 & 51.2 \\
\hline \multicolumn{8}{|l|}{ UV-erythemal dose, $\mathrm{W} / \mathrm{m}^{2}$} \\
\hline Mean (SD) & $8.5(0.5)$ & $8.5(0.5)$ & $8.5(0.6)$ & $8.5(0.6)$ & $8.5(0.6)$ & $8.5(0.6)$ & $8.6(0.6)$ \\
\hline Range & $7.1-13.6$ & $7.1-12.5$ & $7.4-11.2$ & $7.4-11.2$ & $7.4-11.2$ & $7.4-11.2$ & $7.4-11.1$ \\
\hline Interquartile range & 0.7 & 0.7 & 0.7 & 0.7 & 0.7 & 0.7 & 0.7 \\
\hline
\end{tabular}

Note: MM, malignant melanoma; NMSC, non-melanoma skin cancer; S1 $(2,3,4)$, sensitivity analysis $1(2,3,4)$; SD, standard deviation; UV, ultraviolet.

a"Primary" indicates definitive primary cause of death; "All" indicates definitive primary cause of death, comcomitant, consecutive, or initial disease.

${ }^{b}$ Highest completed education/training.

${ }^{c}$ Other job position refers to unemployed or not/no longer in paid employment and includes homemakers and retirees.

engaged in other activities. Furthermore, previous UV exposure from outdoor occupations is not known because we only assessed this covariate at baseline. However, removing retirees, for whom previous outdoor occupation was unknown, did not substantially change the HRs (see Table S4).

Few studies have been conducted on the association between skin cancer and radon. The American Cancer Prevention Study II (CPS-II) cohort found HRs of 1.08 (95\% CI: 0.88, 1.33) and 0.70 (95\% CI: $0.42,1.19)$ per $100 \mathrm{~Bq} / \mathrm{m}^{3}$ in mean county-level residential radon for MM and NMSC mortality, respectively (Turner et al. 2012). Wheeler et al. (2012) found an association between radon and incidence of squamous cell carcinoma (SCC), but not basal cell carcinoma (BCC) or MM, in southwest England; nor did they find an association with incidence of NMSC (SCC and BCC combined) at the national level (Wheeler et al. 2013). In contrast, Bräuner et al. (2015) found a statistically significant association between BCC and radon [HR of 1.14 (95\% CI: 1.03, 1.27) per $100 \mathrm{~Bq} / \mathrm{m}^{3}$ ] but not for SCC or MM in a Danish cohort study. Notably, radon exposure contrasts in England and Denmark are lower than those in Switzerland.

The major strength of our study is the longitudinal data for a large population and information on household location, including floor of residence, enabling an objective assessment of residential exposures. We also incorporated a JEM to include information 

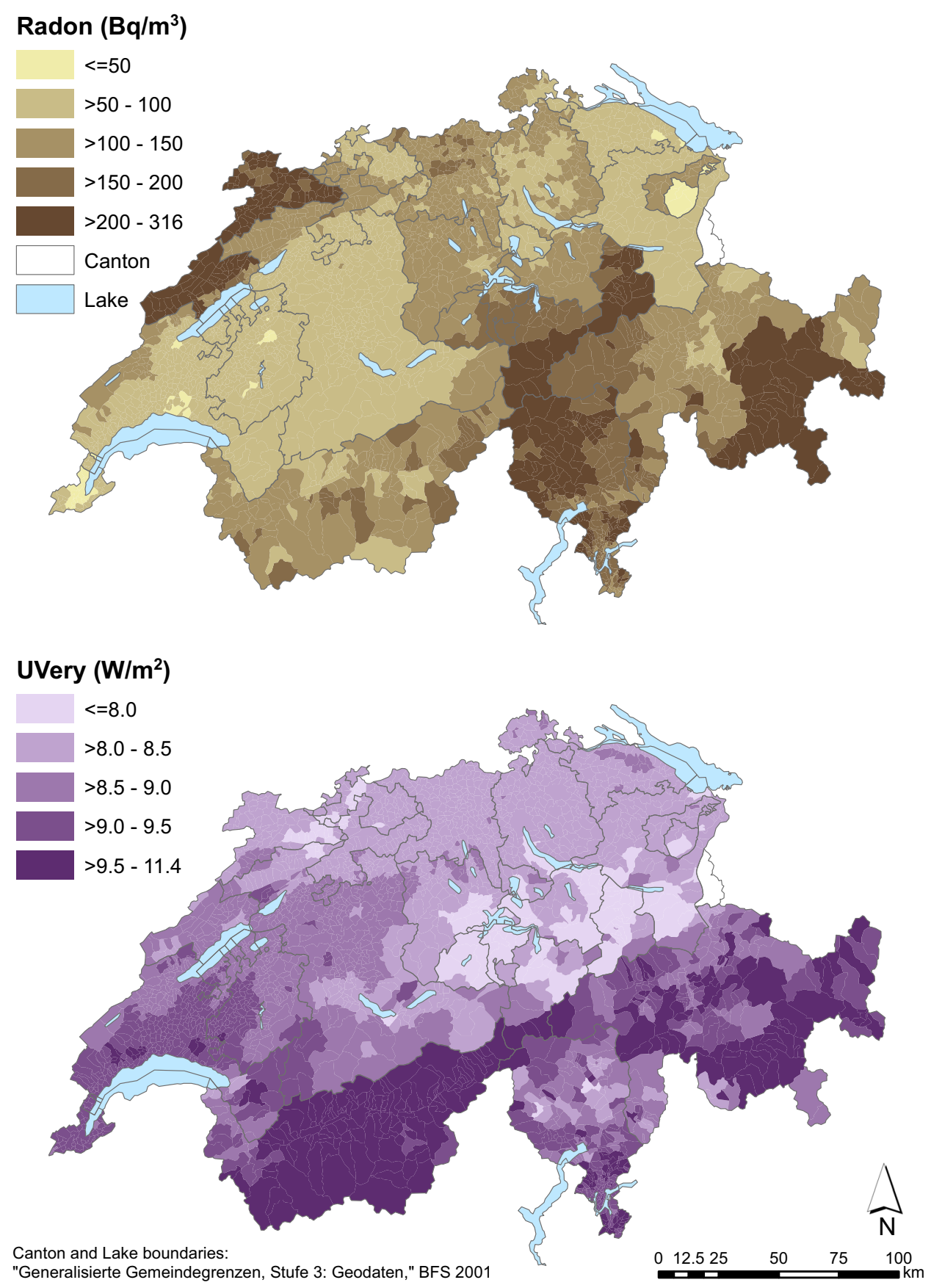

Figure 1. Mean community-level radon $\left(\mathrm{Bq} / \mathrm{m}^{3}\right)$ and UVEry $\left(\mathrm{W} / \mathrm{m}^{2}\right)$ exposure across Switzerland.

about UV exposure from outdoor occupations. Finally, we evaluated a negative control outcome, finding that the associations were not likely to be explained by residual confounding from SEP. As a census-based cohort, however, we lack individual-level data on sun sensitivity and on behaviors that have been shown to be important (i.e., vacationing in sunny locations, use of sun protection, and indoor tanning) (Chang et al. 2014). UV exposure estimated by our residential model is vulnerable to exposure error, although the exposure misclassification is expected to be nondifferential. We also cannot rule out that the associations for radon may be subject to residual confounding by UV exposure given that UV is such a strong risk factor for skin cancer. Correlation between individual UV and radon exposure, however, is very low ( $r=-0.01$, which limits the extent of residual confounding. Without information on sun and tanning behavior, we can only speculate about the impact on our results. For example, in rural areas, people may spend more time outdoors, whereas indoor tanning may be more popular in urban areas. We also acknowledge the somewhat low explained variance in our radon prediction model. The type of error, however, for this kind of exposure model is expected to be mainly Berkson error, which would increase the confidence intervals of our associations rather than lead to biased estimates. Furthermore, we do not have information on cancer sites, although this information may not be helpful for disentangling the effects of radon versus UV given that doses from both exposures are highest for uncovered skin (Eatough and Henshaw 1992).

Switzerland has among the highest mortality rates for malignant melanoma in Europe, with an age-standardized mortality of 4.9 (male) and 2.4 (female) per 100,000 in 2012 compared with 2.8 (male) and 1.7 (female) in the European Union (EU-27) 
Table 2. Hazard ratios ( $95 \%$ confidence intervals) for radon (per $100 \mathrm{~Bq} / \mathrm{m}^{3}$ ) and UV-erythemal dose (per $\left.\mathrm{W} / \mathrm{m}^{2}\right)$ exposure and type of skin cancer mortality, age 60 .

\begin{tabular}{|c|c|c|c|c|c|c|}
\hline \multirow[b]{3}{*}{ Population $^{a}$} & \multirow[b]{3}{*}{ Model } & \multirow[b]{3}{*}{ Deaths $(n)$} & \multicolumn{2}{|c|}{$\operatorname{Radon}^{b}$} & \multicolumn{2}{|c|}{ UV-erythemal dose ${ }^{b}$} \\
\hline & & & \multicolumn{2}{|c|}{$\mathrm{HR}\left(\right.$ per $100 \mathrm{~Bq} / \mathrm{m}^{3}$ ) } & \multicolumn{2}{|c|}{ HR $\left(\right.$ per $\left.1 \mathrm{~W} / \mathrm{m}^{2}\right)$} \\
\hline & & & M1 & M2 & M1 & M2 \\
\hline \multicolumn{7}{|c|}{ Full study sample $(n=5,249,462)$} \\
\hline MM (all) & S1 & 2,157 & $1.12(1.02,1.24)$ & $1.16(1.05,1.28)$ & $0.95(0.88,1.03)$ & $1.08(0.99,1.19)$ \\
\hline $\mathrm{MM}+\mathrm{NMSC}$ (primary) & $\mathrm{S} 2$ & 2,349 & $1.14(1.04,1.25)$ & $1.17(1.06,1.29)$ & $1.02(0.95,1.10)$ & $1.12(1.03,1.23)$ \\
\hline MM + NMSC (all) & S3 & 2,989 & $1.13(1.03,1.24)$ & $1.16(1.05,1.27)$ & $0.99(0.93,1.06)$ & $1.09(1.01,1.18)$ \\
\hline MM (all) & $\mathrm{S} 1$ & 1,549 & $1.15(1.02,1.31)$ & $1.21(1.06,1.37)$ & $0.95(0.86,1.04)$ & $1.08(0.97,1.21)$ \\
\hline MM + NMSC (primary) & $\mathrm{S} 2$ & 1,712 & $1.13(1.00,1.28)$ & $1.17(1.02,1.33)$ & $1.02(0.93,1.11)$ & $1.12(1.01,1.24)$ \\
\hline MM + NMSC (all) & S3 & 2,231 & $1.12(0.99,1.26)$ & $1.15(1.02,1.30)$ & $0.98(0.91,1.06)$ & $1.07(0.98,1.17)$ \\
\hline NMSC (all) & S4 & 687 & $0.84(0.57,1.22)$ & $0.84(0.57,1.22)$ & $1.06(0.92,1.21)$ & $1.04(0.88,1.23)$ \\
\hline
\end{tabular}

Note: HR, hazard ratio; M1 (2), model 1 (2); MM, malignant melanoma; NMSC, non-melanoma skin cancer; S1 (2,3,4), sensitivity analysis 1 (2,3,4); UV, ultraviolet; UVEry, UVerythemal dose.

a“"Primary" indicates definitive primary cause of death; "All" indicates definitive primary cause of death, comcomitant, consecutive, or initial disease.

${ }^{b} \mathrm{M} 1$ is the base model with baseline hazard stratified by sex (radon, UVEry, sex). M2 (adjusted model) is M1 plus adjustments for civil status, educational attainment, socioeconomic position, outdoor occupation with UV exposure, and mother tongue.

${ }^{c}$ Nonmovers had the same address in the 1990 and 2000 censuses as determined by $x$ - $y$ coordinates.

(Ferlay et al. 2013). Although the mortality rate has been relatively stable, the incidence of malignant melanoma in both men and women in Switzerland has more than doubled in the last $20 \mathrm{y}$. Based on the percent share of cancers in Switzerland, incident skin cancer is ranked fifth after breast, prostate, colonrectum, and lung cancer (FSO 2011). By focusing on the most severe outcome, we miss a large portion of the incident cases; approximately $15 \%$ of incidence is captured by mortality (FSO 2011). Known issues about the reliability of coding on death certificates is also a potential limitation. The proportion of represented cases and mistakes in coding, however, are expected to introduce nondifferential misclassification unless the severity of disease is affected by exposure, for which we have no indications in the literature.

Further studies on radon in relation to skin cancer incidence are needed to better understand the role of radon exposure as a risk factor. In Switzerland, radon is already recognized as a public health issue based on the known association between inhalation and lung cancer, and a National Action Plan for 2012-2020 is in place to adapt the existing legislation (i.e., the Radiological Protection Ordinance of 22 June 1994, with a limit value for obligatory remediation at $1,000 \mathrm{~Bq} / \mathrm{m}^{3}$ and a guideline value of $\left.400 \mathrm{~Bq} / \mathrm{m}^{3}\right)(\mathrm{FOPH} 2011)$.
Another question is whether the noted increase in skin cancer incidence is related to better screening and reporting, or if one or both of the considered exposures have also increased in recent years. One obvious factor is the use of sunbeds. Although trends in sunbed use in Switzerland are not available, a recent international meta-analysis including studies from Europe found indications for an increasing trend (Wehner et al. 2014). A crosssectional survey in 2011 in Austria by Haluza et al. (2016) also found high prevalence of self-reported sunbed use, particularly in individuals $18-29$ y old. With regard to radon, our data suggest that concentrations in the living rooms of homes have decreased over time, with levels stabilizing in buildings constructed in the last half of the 20th century (Hauri et al. 2013). In new, yet unpublished measurements, there is some indication of an increase in radon concentrations in new energy-efficient homes (F. Barazza, Scientific Associate, FOPH, email communication, October 2016). This small increase, however, could not explain the observed incidence increase given the magnitude of risk seen in our study for radon.

Because the dose to the lung differs only by a factor of four compared with the dose to the skin (Kendall and Smith 2002), a link between radon and skin cancer may be plausible. Such a link may affect radon guidelines on a global scale (WHO 2009).

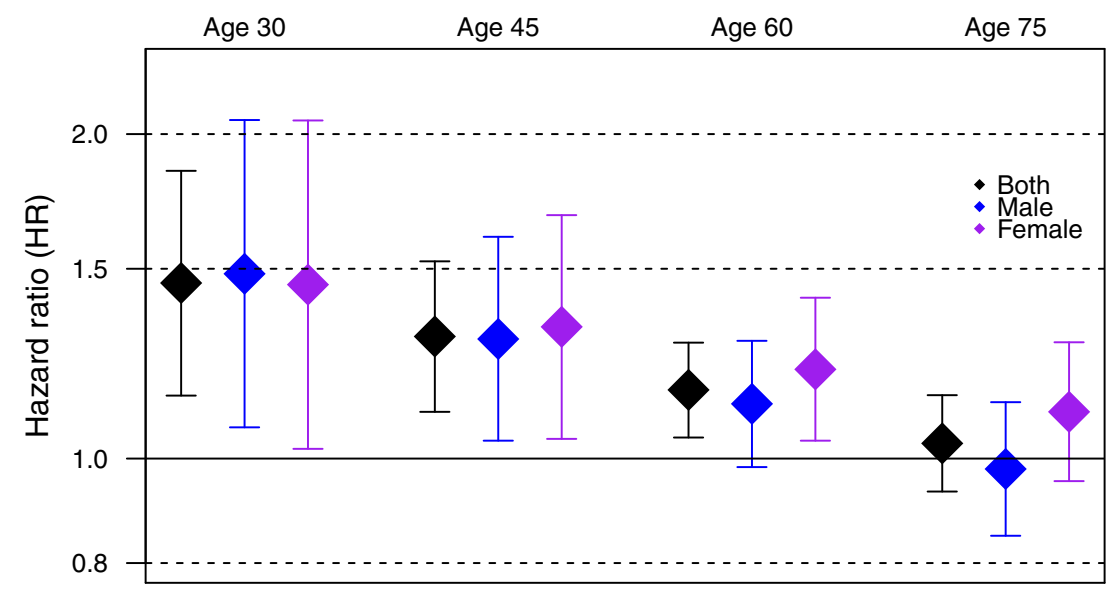

Figure 2. Effect of exposure to radon [hazard ratio (HR) per $100 \mathrm{~Bq} / \mathrm{m}^{3}$ with $95 \%$ confidence intervals] on malignant melanoma mortality by age and sex. 
Table 3. Effect modification for the relationship between radon and UV-erythemal dose and mortality from malignant melanoma, age 60 .

\begin{tabular}{|c|c|c|}
\hline Subgroup & $\frac{\text { Radon }^{a}}{\mathrm{HR}\left(\text { per } 100 \mathrm{~Bq} / \mathrm{m}^{3}\right)}$ & $\frac{\text { UV-erythemal dose }}{\text { HR }\left(\text { per } 1 \mathrm{~W} / \mathrm{m}^{2}\right)}$ \\
\hline \multicolumn{3}{|l|}{$\overline{\operatorname{Sex}}$} \\
\hline Males & $1.14(0.99,1.31)$ & $1.13(1.00,1.29)$ \\
\hline Females & $1.19(1.01,1.39)$ & $1.09(0.94,1.26)$ \\
\hline$p$-value for interaction ${ }^{b}$ & 0.72 & 0.71 \\
\hline \multicolumn{3}{|l|}{ Mother tongue } \\
\hline German & $1.16(1.01,1.34)$ & $1.06(0.94,1.20)$ \\
\hline French & $1.10(0.90,1.35)$ & $1.04(0.82,1.32)$ \\
\hline Italian & $1.25(0.88,1.78)$ & $1.85(1.27,2.67)$ \\
\hline Other & $1.07(0.48,2.38)$ & $1.07(0.60,1.91)$ \\
\hline$p$-value for interaction ${ }^{b}$ & 0.93 & 0.17 \\
\hline \multicolumn{3}{|c|}{$\begin{array}{l}\text { Outdoor occupation with } \\
\text { UV exposure, at baseline }\end{array}$} \\
\hline No & $1.17(1.05,1.31)$ & $1.09(0.99,1.21)$ \\
\hline Yes & $0.95(0.52,1.74)$ & $1.94(1.17,3.23)$ \\
\hline$p$-value for interaction ${ }^{b}$ & 0.45 & 0.09 \\
\hline
\end{tabular}

Note: HR, hazard ratio; UV, ultraviolet.

${ }^{a}$ Reported HRs and 95\% confidence intervals are for the main model, that is, fully adjusted M2 models, for deaths from malignant melanoma.

${ }^{b} p$-value of the Chi-squared test used to assess between-strata heterogeneity.

"No" includes employed individuals working indoors, as well as those not employed or retired (i.e. unexposed to UV from outdoor occupation).

\section{Conclusions}

Information on the risk of radon exposure with regard to skin cancer is limited in the scientific literature. In a large prospective cohort, we found an increased risk of skin cancer mortality in association with household radon levels. The present study supports the hypothesis that radon exposure is a relevant risk factor for skin cancer independent of residential UVEry exposure. Additional studies on this topic are therefore of high public health relevance.

\section{Acknowledgments}

We thank the Swiss Federal Statistical Office for providing mortality and census data, and for the support that made the Swiss National Cohort and this study possible. The members of the Swiss National Cohort Study Group are M. Egger (Chairman of the Executive Board), A. Spoerri, and M. Zwahlen (all Bern), M. Puhan (Chairman of the Scientific Board), M. Bopp (both Zurich), N. Künzli (Basel), F. Paccaud (Lausanne), and M. Oris (Geneva). Appreciation is also extended to J. Fevotte for providing the job exposure matrix. This work was supported by the Swiss National Science Foundation (grants 3347CO-108806, 33CS30_134273, 33CS30_148415, and the SNC nested studies contract number 0080).

\section{References}

Aceituno-Madera P, Buendia-Eisman A, Olmo FJ, Jimenez-Moleon JJ, SerranoOrtega S. 2011. Melanoma, altitude, and UV-B radiation. Actas Dermosifiliogr 102:199-205.

Berwick M, Lachiewicz A, Pestak C, Thomas N. 2008. Solar UV exposure and mortality from skin tumors. Adv Exp Med Biol 624:117-124, PMID: 18348452, https://doi.org/10.1007/978-0-387-77574-6_10.

Bopp M, Spoerri A, Zwahlen M, Gutzwiller F, Paccaud F, Braun-Fahrländer C, et al. 2009. Cohort profile: The Swiss National Cohort-A longitudinal study of 6.8 million people. Int J Epidemiol 38:379-384, PMID: 18326512, https://doi.org/10. 1093/ije/dyn042.

Bräuner EV, Loft S, Sørensen M, Jensen A, Andersen CE, Ulbak K, et al. 2015. Residential radon exposure and skin cancer incidence in a prospective Danish cohort. PLoS ONE 10:e0135642, https://doi.org/10.1371/journal.pone.0135642.

Chang C, Murzaku EC, Penn L, Abbasi NR, Davis PD, Berwick M, et al. 2014. More skin, more sun, more tan, more melanoma. Am J Public Health 104:e92-e99, PMID: 25211764, https://doi.org/10.2105/AJPH.2014.302185.

Charles MW. 2007. Radon exposure of the skin: II. Estimation of the attributable risk for skin cancer incidence. J Radiol Prot 27:253-274, PMID: 17768327, https://doi.org/10.1088/0952-4746/27/3/R02.
Dadvand P, Basagaña X, Barrera-Gómez J, Diffey B, Nieuwenhuijsena M. 2011. Measurement errors in the assessment of exposure to solar ultraviolet radiation and its impact on risk estimates in epidemiological studies. Photochem Photobiol Sci 10(7):1161-1168, https://doi.org/10.1039/c0pp00333f.

Douple EB, Mabuchi K, Cullings HM, Preston DL, Kodama K, Shimizu Y, et al. 2011. Long-term radiation-related health effects in a unique human population: Lessons learned from the atomic bomb survivors of Hiroshima and Nagasaki. Disaster Med Public Health Prep 5 Suppl (1):S122-S133, https://doi.org/10.1001/dmp.2011.21.

Eatough JP, Henshaw DL. 1992. Radon and thoron associated dose to the basal layer of the skin. Phys Med Biol 37:955, PMID: 1317037.

Eatough JP. 1997. Alpha-particle dosimetry for the basal layer of the skin and the radon progeny 218-po and 214-po. Phys Med Biol 42:1899, PMID: 9364586.

Ferlay J, Steliarova-Foucher E, Lortet-Tieulent J, Rosso S, Coebergh JW, Comber $\mathrm{H}$, et al. 2013. Cancer incidence and mortality patterns in europe: Estimates for 40 countries in 2012. Eur $\mathrm{J}$ Cancer 49:1374-1403.

FOPH (Federal Office of Public Health). 2011. National Action Plan Concerning Radon 2012-2020. Köniz, Switzerland:Federal Office of Public Health.

FSO (Federal Statistics Office). 2011. Cancer in Switzerland: Situation and development from 1983 to 2007. http://www.nicer.org/assets/files/publications/ others/krebs_in_der_schweiz_e_web.pdf [accessed 3 April 2016].

FSO. 2013. Swiss Health Survey 2012 Overview. https://www.bfs.admin.ch/bfs/en/ home/statistics/health.assetdetail.349060.html [accessed 3 April 2016].

Greenland S. 1989. Modeling and variable selection in epidemiologic analysis. Am J Public Health 79:340-349, PMID: 2916724.

Guénel P, Laforest L, Cyr D, Févotte J, Sabroe S, Dufour C, et al. 2001. Occupational risk factors, ultraviolet radiation, and ocular melanoma: A casecontrol study in France. Cancer Cause Control 12:451-459, PMID: 11545460.

Haluza D, Simic S, Moshammer H. 2016. Sunbed use prevalence and associated skin health habits: Results of a representative, population-based survey among Austrian residents. Int J Environ Res Public Health 13(2):231, PMID: 26907308, https://doi.org/10.3390/ijerph13020231.

Hauri DD, Huss A, Zimmermann F, Kuehni CE, Röösli M. 2012. A prediction model for assessing residential radon concentration in Switzerland. J Environ Radioact 112:83-89, PMID: 22683900, https://doi.org/10.1016/j.jenvrad.2012.03.014.

Hauri DD, Huss A, Zimmermann F, Kuehni CE, Röösli M. 2013. Prediction of residential radon exposure of the whole Swiss population: Comparison of modelbased predictions with measurement-based predictions. Indoor Air 23:406-416 PMID: 23464847, https://doi.org/10.1111/ina.12040.

IARC (International Agency for Research on Cancer). 2001. Ionizing radiation, part 2: Some internally deposited radionuclides. IARC Monog Eval Carcinog Risk Hum 78:1-559. http://monographs.iarc.fr/ENG/Monographs/vol78/ [accessed 3 April 2016].

IARC. 2001. Globocan 2012: Estimated cancer incidence, mortality and prevalence worldwide. http://globocan.iarc.fr [accessed 25 0ctober 2016].

IARC 2013 Kendall GM, Smith TJ. 2002. Doses to organs and tissues from radon and its decay products. J Radiol Prot 22:389-406, PMID: 12546226.

Khanolkar AR, Ljung R, Talback M, Brooke HL, Carlsson S, Mathiesen T, et al. 2016. Socioeconomic position and the risk of brain tumour: A swedish national population-based cohort study. J Epidemiol Community Health.

Krewski D, Lubin JH, Zielinski JM, Alavanja M, Catalan VS, Field RW, et al. 2006. A combined analysis of North American case-control studies of residential radon and lung cancer. J Toxicol Environ Health Part A 69:533-597, PMID: 16608828, https://doi.org/10.1080/15287390500260945.

Lipsitch M, Tchetgen ET, Cohen T. 2010. Negative controls: A tool for detecting confounding and bias in observational studies. Epidemiology 21:383-388, https://doi.org/10.1097/EDE.0b013e3181d61eeb.

McKenzie R, Smale D, Kotkamp M. 2004. Relationship between uvb and erythemally weighted radiation. Photochem Photobiol Sci 3:252-256, PMID: 14993940, https://doi.org/10.1039/b312985c.

Menzler S, Piller G, Gruson M, Rosario AS, Wichmann HE, Kreienbrock L. 2008. Population attributable fraction for lung cancer due to residential radon in Switzerland and Germany. Health Phys 95:179-189, PMID: 18617799, https://doi.org/10.1097/01.HP.0000309769.55126.03.

MeteoSwiss (Federal Office of Meteorology and Climatology). 2017. UV Measurements. http://www.meteoswiss.admin.ch/home/measurement-and-forecastingsystems/atmosphere/radiation-monitoring-network/uv-measurements.html [accessed 19 May 2017].

Moehrle M, Garbe C. 1999. Does mountaineering increase the incidence of cutaneous melanoma? A hypothesis based on cancer registry data. Dermatology (Basel) 199:201-203, PMID: 10592397.

Panczak R, Galobardes B, Voorpostel M, Spoerri A, Zwahlen M, Egger M. 2012. A Swiss neighbourhood index of socioeconomic position: Development and association with mortality. J Epidemiol Community Health.

Renaud A. 2004. Coverage Estimation for the Swiss Population Census 2000: Estimation Methodology and Results. Neuchâtel, Switzerland:Swiss Federal Statistical Office. 
Stöckli R. 2013. The HelioMont Surface Solar Radiation Processing, Scientific Report MeteoSwiss, Edition 93. http://www.meteoswiss.admin.ch/home/climate/ past/solar-energy.subpage.html/en/data/publications/2013/5/the-heliomont-surfacesolar-radiation-processing-.html [accessed 19 May 2017].

Swisstopo (Swiss Federal Office of Topography). 2004. DHM25 The digital height model of Switzerland. https://shop.swisstopo.admin.ch/en/products/height_ models/dhm25 [accessed 19 May 2017].

Turner MC, Krewski D, Chen Y, Pope CA, Gapstur SM, Thun MJ. 2012. Radon and nonrespiratory mortality in the American Cancer Society cohort. Am J Epidemiol.

Wehner MR, Chren MM, Nameth D, Choudhry A, Gaskins M, Nead KT, et al. 2014. International prevalence of indoor tanning: A systematic review and metaanalysis. JAMA Dermatol 150:390-400, PMID: 24477278, https://doi.org/10.1001/ jamadermatol.2013.6896.
Wheeler BW, Allen J, Depledge MH, Curnow A. 2012. Radon and skin cancer in southwest England: An ecologic study. Epidemiology 23:44-52, PMID: 22081061, https://doi.org/10.1097/EDE.0b013e31823b6139.

Wheeler BW, Kothencz G, Pollard AS. 2013. Geography of non-melanoma skin cancer and ecological associations with environmental risk factors in England. Br J Cancer 109:235-241, PMID: 23756856, https://doi.org/10.1038/bjc. 2013.288.

WHO (World Health Organization). 2006. Physical Activity and Health in Europe: Evidence for Action. Copenhagen: World Health Organization.

WHO. 2009. WHO Handbook on Indoor Radon: A Public Health Perspective. Geneva: World Health Organization.

WHO. 2016. International Statistical Classification of Diseases and Related Health Problems, 10th Edition. http://apps.who.int/classifications/icd10/browse/2016/ en [accessed 19 May 2017]. 